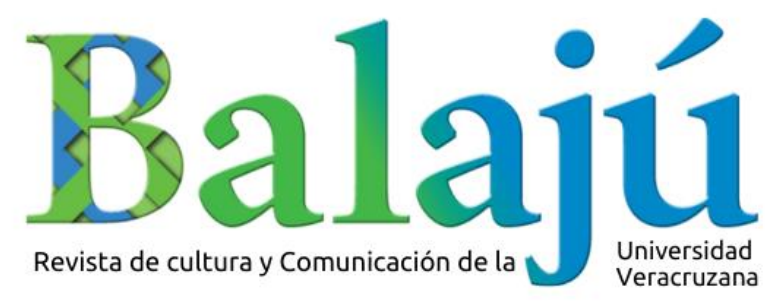

\title{
Movimientos sociales. Una reflexión teórica sobre las irrupciones sociales hasta 2019 en México y en Chile
}

\author{
Jaime González González, Rubén Ramírez \\ Sánchez y Daniar Chávez Jiménez \\ Centro de Educación y Cultura Americana (CECA) \\ Universidad Nacional Autónoma de México \\ Recibido: 28-05-2020 | Aceptado: 29-11-2020
}




\title{
Balajú
}

Movimientos sociales. Una reflexión teórica sobre las irrupciones sociales hasta 2019 en México y en Chile

\section{Social movements: A Theoretical Reflection on Social Irruptions through 2019 in Mexico and Chile}

\author{
Jaime González González ${ }^{1}$ \\ Rubén Darío Ramírez Sánchez ${ }^{2}$ \\ Daniar Chávez Jiménez ${ }^{3}$
}

\section{Resumen}

Este ensayo ofrece una reflexión teórica sobre el concepto de movimiento social desde los casos de México y Chile. La pregunta directriz interroga sobre las semejanzas de los movimientos sociales recientes en estos países. Frente a esto, se sugiere como hipótesis que existen similitudes del objeto en ambos casos, observables en: 1) el contexto de crisis de legitimidad del orden establecido, y 2) el manejo medial a través de redes digitales por parte de los movimientos para manifestar sus causas. Se concluye que existen semejanzas en los movimientos sociales de los casos contemplados, vinculadas a la presencia de una cultura cosmopolita operando en las prácticas de los individuos participantes en las movilizaciones. En este sentido, el análisis matiza la condición subalterna del objeto, considerando el papel de agentes urbanos, cosmopolitas e instruidos participando en la orientación cultural/identitaria de los movimientos. En un contexto de crisis de legitimidad en los estilos de hacer política, la opinión de agentes de alta escolaridad en plataformas digitales genera una ventana de oportunidad para el cambio en la configuración de las instituciones.

Palabras clave: movimiento social, cultura política, identidad, opinión

\begin{abstract}
This article offers a theoretical reflection on the concept of social movement, utilizing the cases of Mexico and Chile. Its central question is in regard to similarities between recent social movements in these countries, posing the hypothesis that there are resemblances observable in: 1) the context of crisis of legitimacy of the established order, and 2) media management through digital networks by the

\footnotetext{
1 Centro de Educación y Cultura Americana, Chile. ORCID: 10.29344/07196458.23.1857. Correo: jagonzag1974@gmail.com.

${ }^{2}$ Unidad Académica de Estudios Regionales de la Coordinación de Humanidades de la UNAM, México. ORCID: 0000-0002-8766-0233. Correo: rubendario105@ hotmail.com.

${ }^{3}$ Unidad Académica de Estudios Regionales de la Coordinación de Humanidades de la UNAM, México. ORCID: 0000-0002-4116-3223. Correo: daniarc@yahoo.com.
} 
movements in order to manifest their causes. It concludes that there are, in effect, similarities between the social movements of the cases considered, and that these are linked to the presence of a cosmopolitan culture operating in the practices of individuals participating in the mobilizations. The analysis thus takes into account the subaltern condition of its object, highlighting the role of urban, cosmopolitan and educated agents participating in the cultural/identity orientation of the movements. In the context of a crisis of legitimacy in the political sphere, the opinion of highly educated agents utilizing digital platforms generates a window of opportunity for change in the configuration of institutions.

Keywords: social movements, political culture, identity, opinion 


\title{
Balajú
}

\section{MOVIMIENTOS SOCIALES. UNA REFLEXIÓN TEÓRICA SOBRE LAS IRRUPCIONES SOCIALES HASTA 2019 EN MÉXICO Y EN CHILE}

\author{
Jaime González González \\ Rubén Darío Ramírez Sánchez \\ Daniar Chávez Jiménez
}

\section{Introducción}

En el transcurso de 2019 se observó una serie de fenómenos sociales y políticos que cuestionaron tanto a gobiernos como al orden establecido en América Latina; sacudieron a los gobiernos de Venezuela, Ecuador, Bolivia, Chile y México, generando un escenario político conflictivo en la región. El fenómeno se presentó dentro de un contexto mundial de protestas y de estallido social en contra de las políticas públicas gubernamentales encaminadas a reducir o a desmantelar la seguridad social.

Los movimientos colectivos de protesta no constituyen un fenómeno nuevo en la historia de la humanidad. Desde la Revolución francesa de 1789, se observa una serie de fenómenos que las ciencias sociales han conceptuado como "movimiento social" (Giddens, 2000). En este terreno destaca la propuesta de Alain Touraine (2006), quien define el concepto como el comportamiento colectivo organizado por parte de un actor social contra un adversario, por la dirección social de lo que Touraine llama la "historicidad" en una colectividad concreta. Para el sociólogo francés, no se pueden separar las orientaciones culturales y el conflicto social, ya que esto no ha ocurrido en las sociedades del pasado. Desde esta perspectiva, el concepto debe ser abordado desde el campo cultural (la historicidad de una sociedad), entendido como el conjunto formado por los actores sociales y por lo que él llama el enjeu, es decir, lo que está en juego en la lucha social.

Sidney Tarrow (1997) realizó observaciones semejantes al analizar los fundamentos del concepto en las redes sociales y los símbolos culturales a través de los cuales se estructuran las relaciones sociales. Tarrow indica que todo movimiento social dispone de estos cimientos y se ponen en movimiento a la hora que se presenta la oportunidad política para la intervención de colectivos que normalmente carecen de poder. En este terreno, el autor norteamericano hace hincapié en lo que llama "acción colectiva contenciosa", que a su juicio constituye al acto irreductible que subyace a todos los movimientos. 


\section{Balajú}

Lo que se desprende de estos razonamientos es que los movimientos sociales se nutren de agentes subalternos, en el sentido gramsciano del término. Estos se activan como "poder en movimiento" cuando se presenta una ventana de oportunidad política para intervenir en la escena social local, nacional o internacional. Los fundamentos de estos movimientos se encuentran tanto en las redes sociales de organización propias como en los estilos de vida que les aportan identidad, cimientos que, junto a la historia y los objetivos (el enjeu) de la colectividad que entra en movimiento, permiten accionar una escena social y política local nacional e internacional para enfrentar a grupos "mejor posicionados" que ellos para contenerlos o reprimirlos.

Un aspecto relevante de esta discusión tiene que ver con lo que Tarrow llama “oportunidad política”. Para que los colectivos subalternos se activen como movimiento social, resulta relevante que se presente la escena de poder que los habilite para intervenir en un contexto nacional. Esta oportunidad se vincula al problema de la legitimidad de un gobierno o de un orden establecido, lo que lleva al abordaje del concepto de cultura política y su maridaje teórico con las ideas de legitimidad y movimiento social. Si definimos la cultura política como un "estilo de hacer política" (Ramírez y González, 2018), podemos sostener que los modos de realizarla disponen de un fundamento simbólico llamado legitimidad (Weber, 2002), la cual constituye una dimensión de las representaciones colectivas ligada a la interpretación que individuos y grupos llevan a cabo en torno a lo que se considera válido en el terreno de las prácticas de poder. De esta manera, existen acciones políticas legítimas e ilegítimas y -a diferencia de la legalidad en política- su condición va a depender de la interpretación de una población determinada. Así, la distinción entre lo que es legítimo y lo que es ilegítimo va a depender tanto de la cultura vigente en una sociedad como del terreno de identificación/adscripción política de los grupos que conforman un país. De esta manera, existe un nexo entre cultura política, legitimidad e identidad política, vínculo que, si llegara a entrar en tensión, podría generar una ventana de oportunidad nacional a colectivos subalternos para intervenir en escena.

Estas oportunidades políticas constituyen las crisis de legitimidad en las instituciones. Cuando la práctica política cotidiana deja de ser válida para los ojos de la población, se entra a un contexto de crisis de legitimidad, momento que puede ser aprovechado por colectivos que han sido marginados históricamente. Es en esta escena que individuos y grupos resignifican los símbolos de poder dominantes, dando paso a la formulación de nuevas identificaciones 


\section{Balajú}

políticas en el plano de los grupos de interés, los partidos políticos u otras organizaciones sociales. No obstante, tanto las ventanas de oportunidad como la activación de los movimientos sociales se desarrollan en un contexto social. En este sentido, no es lo mismo el fenómeno en países o áreas metropolitanas, que en las periferias del desarrollo tecnológico y productivo o en zonas rurales. En este punto nos parece relevante la reflexión realizada por Lorenzo Meyer (2012) en torno a la dicotomía existente entre conceptos y contextos: las nociones de ciencia social elaboradas en países centrales pueden entrar en tensión en países o áreas periféricas. Esta tensión puede estar ligada tanto al desconocimiento del contexto (Nohlen, 2008) como al acto de forzar las nociones a la realidad, lo que conduce a un "estiramiento conceptual" (Sartori y Morlino, 1999). De esta manera, resulta fundamental ligar la discusión sobre los movimientos sociales en el lugar social en que se encuentran situados, para no caer en situaciones de tensión teórica con el contexto en que se reflexiona.

Este trabajo busca reflexionar en el concepto de movimiento social, considerando a México y a Chile como casos históricos ilustrativos. A pesar de la diversidad de movimientos y escenarios, se observa un patrón común, ligado tanto a la crisis del proceso de la globalización neoliberal en el mundo como a la condición periférica de los casos mismos. En tal sentido, este estudio se esfuerza en analizar los fenómenos más allá de los marcos nacionales en que son definidos por la literatura. De esta manera, nos valemos principalmente del enfoque proporcionado por la teoría del sistema mundial (Wallerstein, 1979, 1997, 2006), para aproximarnos a los movimientos sociales latinoamericanos. La pregunta directriz de este ensayo es: ¿cuáles son las semejanzas entre los movimientos sociales de México y de Chile? Se sugiere como hipótesis que las similitudes entre estos movimientos se observan en dos niveles: 1) el contexto de crisis de legitimidad del orden establecido, y 2) el manejo medial mediante redes digitales por parte de los movimientos para manifestar sus causas.

\section{Ruta crítica sobre el concepto de movimiento social}

El estudio de los movimientos sociales (MS) conforma una amplia estela de propuestas teóricas que permiten diversificar su reflexión. En este ámbito, prevalece la Escuela Europea o Escuela de los Nuevos Movimientos Sociales, representada por Alain Touraine (1997) y Alberto Melucci (1999), la cual considera que este tipo de movimientos emergen en los cambios estructurales que genera el capitalismo posindustrial y que, mediante el estudio de sus elementos identitarios o simbólicos, es posible cuestionar la lógica del capital y plantear la 


\section{Balajú}

necesidad de un nuevo orden civilizatorio. Esta corriente ha considerado la identidad y los aspectos culturales compartidos por los sujetos como los elementos centrales que los motivan a emprender una acción colectiva y a construir símbolos identitarios cuya base es la solidaridad (Ramírez y González, 2018: 34). ${ }^{4}$ Así, desde la sociología de la acción (la teoría del actor), Touraine y Melucci distinguen las conductas colectivas, las luchas y los MS como actores centrales de las sociedades y la importancia que tienen en el conflicto social como proyecto cultural, considerando que la fuerza de los nuevos movimientos está en su mensaje y no en su estructura.

Una segunda perspectiva de análisis de los MS es la escuela norteamericana, representada por McAdam et al. (1996), quienes desde una perspectiva comparada consideran que la emergencia y la acción de los MS se da a partir de los cambios institucionales u oportunidades que el propio sistema político genera, donde pareciera que los individuos carecen de capacidad para reactuar y cambiar el rumbo de la realidad. Ellos proponen estudiar los MS a partir de las estructuras de oportunidades políticas, que involucran una serie de factores políticos que median en el surgimiento y el desarrollo de los movimientos políticos; las estructuras de movilización, que refiere a los conductos colectivos formales e informales mediante los cuales la gente consigue participar en la acción colectiva; y los procesos enmarcadores o marcos interpretativos de la acción colectiva, que implican los significados e ideas compartidas mediante las cuales la gente define la situación que le lleva a participar en la acción colectiva (McAdam et al., 1996: 24-26).

Y, por último, a principios del siglo XXI emergió una nueva corriente de estudio, alimentada por las dos anteriores, la cual se propuso analizar la nueva clasificación de los movimientos sociales antisistémicos en el nuevo siglo en América Latina, y centró el debate en la "nueva política" y las nuevas experiencias democráticas en este tipo de movimientos, tales como las diversas luchas por la autonomía territorial y cultural, la construcción de nuevas relaciones sociales regidas por la idea zapatista de "mandar obedeciendo" (Rojas, 2010, en Ramírez y González, 2018: 39), así como las limitaciones que estos movimientos presentan

\footnotetext{
${ }^{4}$ El concepto de identidad presenta una amplia polisemia en la ruta crítica sobre la acepción. Producto de esto, en este artículo nos valemos del modelo de "campo identitario regional", formulado por Jorge Iván Vergara y Hans Gundermann (2012), para reflexionar sobre esta noción en torno a escenas locales y supralocales. Complementamos esta perspectiva con el concepto de "identidad colectiva" formulado por Amartya Sen (2008). El mencionado enfoque aporta elementos para el análisis, al entender la identidad como un concepto plural, que pierde esta condición al momento en que la política organizada alinea a los sujetos en una etiqueta simbólica singular.
} 


\section{Balajú}

como proyecto político. A la par, otros estudios han centrado su análisis en las nuevas dinámicas de protesta, la ausencia de líderes, la asamblea como mecanismo de deliberación, basadas fundamentalmente en el uso de las tecnologías de la información y la comunicación y su dimensión trasfronteriza para intercambiar experiencias y mostrar solidaridad (Castells, 2009).

La irrupción de las tecnologías de la información y la comunicación, además, transformó radicalmente la forma de participar y de consolidar los nuevos MS. Con la llegada de las redes sociales, como Messenger, Facebook, Twitter, Instagram o LinkedIn, presenciamos un importante cambio en la comunicación, pero no solo en los entornos personales, familiares, laborales, académicos o de ocio, sino también en la forma en la que los MS experimentaron su inevitable evolución.

Con la normalización del uso de las redes sociales, muy pronto los movimientos dejaron de ver estas herramientas como "simples espacios comunicativos" y comenzaron a transformarlos en "espacios de acción y protesta" (Candía, 2014: 12). Como explica Guiomar Rovira: "Los movimientos sociales son espacios comunicativos y de acción donde se comparten experiencias de lucha y de autoorganización, donde vive cierta reflexividad y se construye un sentido compartido de la protesta. Más allá de una morfología social, las redes sociales se han convertido en un modelo para formas emergentes de política" (Rovira, en Candía, 2014: 12).

A juicio de Gabriela Candía, es importante resaltar que las redes sociales no solo representan la necesidad natural de uso y de apropiación de las nuevas tecnologías, propias de las expresiones sociales actuales, sino que, además, para los MS constituyeron una plataforma de organización colectiva no jerárquica, más democrática y con una estructura horizontal que rompe los modelos verticales de los MS del siglo XX, lo que abre nuevas perspectivas de participación colectiva y reconfigura el perfil tradicionalmente pasivo que caracterizaba a la mayoría de los integrantes que conformaban cualquier grupo. Esta transformación puede observarse en MS como la Primavera Árabe, el Movimiento 15M y los Indignados, entre muchos otros, cuya característica principal es la ausencia de un líder moral (Candía, 2014: 12) y cuya apuesta es la participación activa (o por lo menos en igualdad de circunstancias) de todos los participantes. ${ }^{5}$

\footnotetext{
${ }^{5}$ Candía considera fundamental, siguiendo a Rovira y a Juris, poner atención a las tres dimensiones actuales del activismo en las redes sociales: "1. Formal: la red es una estructura organizativa sin centro. 2. Tecnológica: la red cuenta con una infraestructura basada en las tecnologías de la información y la comunicación (TIC); sobre todo
} 


\section{Balajú}

Recordemos que, de acuerdo con Castells (1999), los MS son las acciones colectivas conscientes que generan transformaciones en los valores institucionales de una sociedad, que se derivan de las experiencias de victorias y derrotas de estos. En este sentido, los MS constituyen esfuerzos y desafíos colectivos, articulados a partir de objetivos comunes (León, 2015: 15). De acuerdo con Riechman y Fernández (1994: 27), “es la manifestación consciente de la acción colectiva que transgrede los límites institucionales. Es un agente colectivo que interviene en el proceso de transformación social promoviendo cambios u oponiéndose a ellos".

Un último cuerpo teórico se funda en el análisis de múltiples movimientos sociales, fundados en el reclamo por tierras, en el conflicto ciudadano protagonizado por seguidores de líderes políticos o en movimientos de autonomía socioambiental. Junto a estas investigaciones, destacan perspectivas centradas en la movilización legal para atenuar la inseguridad del país, producto de la prohibición del consumo de drogas (Martínez, 2015), como también análisis centrados en los movimientos LGTB y el papel de la "difusión relacional" en la construcción de estrategias y discursos legales (Martínez, 2020). A pesar de la diversidad de problemáticas, se observan ciertos elementos comunes ligados a la condición subalterna de los colectivos sociales que protagonizan estos movimientos. Sea por razones materiales, de seguridad o de género, los actores que protagonizan la movilización corresponden a grupos que ocupan lugares subordinados en la estructura social de sus países.

Los MS configuran reivindicaciones colectivas de grupos sociales para defender causas y demandas comunes o que comparten proyecto sobre una forma de organización social. Pueden adoptar distintos tipos de organización, estrategias de movilización, transitar por canales no institucionales mediante huelgas, marchas, mítines, sentadas u otras tácticas, cuyas formas de acción colectiva son no convencionales, enmarcadas en mecanismos disruptivos pacíficos como la resistencia civil, o acciones que pueden tornarse violentas (Tilly, 1995, en Ramírez y González, 2018: 63). En ciertas coyunturas, los MS pueden asumir una perspectiva político electoral, cuya acción tiene como finalidad básica la búsqueda del poder, que puede devenir en la conformación de partidos políticos y encauzar sus luchas mediante canales convencionales. De acuerdo con Ramírez y González (2018: 64), para cumplir sus objetivos y estrategias los MS combinan una doble lógica: "Por un lado, son instrumentos o canales de participación en el proceso político y se proponen obtener de esa participación determinados

con la llegada de los celulares con internet uno puede estar informado de lo que sucede en cualquier parte del mundo, donde se encuentren, no importa la hora, ni el lugar. 3: Normatividad: la red es una utopía: hacer posible aquí y ahora otro mundo posible (Wellman, 2013, en Candía, 2014: 13). 


\section{Balajú}

resultados prácticos, lo que los obliga a entrar en contacto con el poder establecido, ya sea para confrontarlo, ya sea para negociar con él”. En suma, los MS expresan una amplia tipología que emergen a partir de la existencia de un conflicto y se unen mediante elementos identitarios, pueden articularse con otros movimientos para fortalecer y hacer efectivas sus causas y demandas, y pueden modificar los valores de la sociedad establecida (Touraine, 1997; Melucci, 1999; Castells, 2009).

De esta ruta crítica se desprende que los movimientos sociales se nutren de una diversidad de agentes subalternos que enfrentan al poder dominante al presentarse condiciones de oportunidad política para accionar. La movilización de los individuos se funda tanto en las redes sociales de apoyo ${ }^{6}$ como en los aspectos simbólicos que les sirven de cemento social para activar y sostener la acción política contra el orden establecido. No obstante, de la discusión también se desprenden ciertos vacíos conceptuales ligados tanto a la condición subalterna de los movilizados como a la dimensión política de los movimientos. De estas lagunas tratarán las siguientes líneas.

\section{La noción de movimiento social: una propuesta de aproximación conceptual}

Considerando los principales planteamientos de esta ruta crítica sobre el concepto de movimiento social, se observa cómo esta literatura es diversa tanto en el ámbito epistemológico como en el plano teórico. De este debate se desprende que los movimientos sociales son resultado de patrones materiales así como de entornos simbólicos. Sin embargo, llama la atención cómo este poder en movimiento se presenta en países metropolitanos, en contraste con las regiones periféricas del mundo. En el caso de América Latina, la distinción entre dominantes y subalternos se observa a ratos porosa a la hora de considerar aspectos políticos ligados a la acción de los bróker en procesos de intermediación social a nivel local y supralocal. Una situación semejante se observa en los diversos casos de movimientos indígenas, donde la etnicidad y las élites étnicas cumplen un papel clave en los procesos de movilización. Una dimensión no menor la constituye el papel de los agentes intelectuales -estudiantiles y profesionales- en la articulación y dirigencia de estos movimientos. Los factores mencionados

\footnotetext{
${ }^{6}$ El uso de las redes por parte de los movimientos sociales, transfiguró radicalmente sus modelos de operación y organización, al tiempo que los ayudó a reestructurarse y a reunirse "de manera más rápida y más ordenada, permitiendo una enorme eficacia para convocar de forma viral protestas tanto locales como internacionales tratándose de círculos de confianza interpersonales y a la vez de microblogging potenciados por el uso de dispositivos digitales móviles [...] que refundan los mensajes y extienden las denuncias o las convocatorias en tiempo real" (Rovira, en Candía, 2014: 18),
} 


\section{Balajú}

matizan la condición "subalterna" del concepto de movimiento social formulada por las anteriores aproximaciones teóricas. En este apartado realizaremos el esfuerzo por definir una propuesta de aproximación teórica al objeto.

Como dijimos en el capítulo introductorio, una condición básica para la activación de los movimientos sociales se encuentra en la generación de una oportunidad política proveniente desde la cúspide de la pirámide social. Dicho en otras palabras, para que una colectividad subalterna se active como movimiento social, resulta relevante que se presente la escena de poder que los habilite para intervenir en un contexto territorial determinado. Esta habilitación pasa por una crisis de legitimidad en las instituciones sociales que le dan soporte al orden establecido, fundamento que se vincula a la idea de cultura política. El concepto de cultura política fue formulado originalmente por Gabriel Almond y Sidney Verba (1963), quienes lo entendieron como un conjunto de prácticas e interpretaciones en torno al accionar de la política. Sobre esta base formularon una serie de tipologías en torno a la acepción, tales como "cultura política parroquial”, "cultura política de súbdito" o "cultura política de participación”. Junto a ello propusieron la noción de "cultura cívica" como una forma de cultura política que permitía intermediar entre culturas tradicionales y estilos modernos de hacer política. Tributando abiertamente a enfoques antropológicos como el "difusionismo" y el de "cultura y personalidad", buscaron proponer un modelo útil para difundir la democracia desde el terreno cultural.

No obstante, esta perspectiva no contempló otras lecturas antropológicas que permitían comprender y explicar el comportamiento humano desde el concepto de cultura. Así se entiende la perspectiva que propone Héctor Tejera Gaona (1996) cuando, tributando al concepto de "retribalización" formulado por Abner Cohen, define la cultura política como el manejo político de la cultura. Este contrapunto no solo da cuenta de otras lecturas subjetivistas en torno al objeto, sino también de la condición estática del concepto propuesto originalmente por los autores norteamericanos.

En este terreno resulta útil considerar otras perspectivas de la antropología cultural que definen el concepto de cultura como "estilo de vida" (Harris, 2003). Si el objeto se vincula a una forma cotidiana de vivir, puede aportar elementos para entender la cultura política como una forma de hacer política, tal como lo proponen Ramírez y González (2018). Desde esta última lectura, se propone una distinción conceptual entre la idea de cultura política y la noción de "identidad política", al definir esta como el acto de identificación y de adscripción de los 


\section{Balajú}

individuos a distintas comunidades políticas (Ramírez y González, 2018). Es precisamente desde el terreno de la identidad que individuos y colectivos consideran legítimo o ilegítimo un estilo de hacer política. No obstante, a pesar del valor heurístico de esta propuesta, nos encontramos nuevamente con que el enfoque presenta limitaciones en su objetivación en el espacio. Fundando el análisis en variables sociales y políticas domésticas, se descuida en esta aproximación el papel de factores sistémicos globales, tanto económicos como políticos.

En esta dirección es que Immanuel Wallerstein (2006) aporta su concepto de "geocultura". Al sostener que el contexto económico mundial presenta la convivencia de una serie de culturas particulares, junto a una cultura global -geocultura- ligada al sistema mundo, da cuenta de un estilo de vida mundial que se puede observar en distintas latitudes del planeta. De esta manera, al proponer un concepto que hace alusión a una forma de vida presente en distintas colectividades en el globo, podemos considerar que el debate sobre el concepto de cultura política debe tomar en cuenta esta propuesta. A nuestro juicio, esta cultura global se puede observar en ciertas prácticas cosmopolitas que podrían darle otro significado a la idea de "cultura cívica". En este sentido, las vivencias en estilos de vida reconocibles en distintos lugares del globo generarían un tipo de cultura política propia de sujetos urbanos, cosmopolitas y con altos grados de instrucción. Estos agentes pueden convertirse en protagonistas en situaciones de movilización política en contextos de crisis de legitimidad, tal como ha sido estudiado en el caso de los movimientos indígenas en América Latina. En este terreno, estudiantes universitarios y profesionistas pueden convertirse en los principales agentes de movimientos sociales. En contextos de coyuntura histórica (Wallerstein, 1997), estos sujetos pueden participar desde el terreno de la opinión y la dirigencia en la articulación de los movimientos mismos. Para el caso particular de los discursos, estos sujetos pueden convertirse en agentes de opinión pública gracias a las nuevas tecnologías de la información. Si consideramos la noción de "opinión pública" formulada por Jürgen Habermas (2009) entendiendo por tal la publicación del común raciocinio de un conjunto de sujetos elitarios-, se puede sostener que estos individuos pueden convertirse en actores clave en los procesos de significación y resignificación de la legitimidad de las instituciones sociales.

Esto hecho se potencializó en 2004, con el surgimiento de la Web 2.0 o Web social, que permitió a los usuarios con conocimientos tecnológicos poder convertirse no solo en receptores de información, sino también en creadores de contenidos. El advenimiento de la Web 3.0 amplió enormemente el poder de participación de ciertos sectores de la población mundial que 


\section{Balajú}

se convirtieron en actores dentro de la acción colectiva de la formación de contenidos. Así, los espacios de opinión e información ampliaron sus fronteras, "a diferencia de los medios de comunicación masivos (prensa, radio y televisión), que suelen ser medios centralizados, con poco acceso, verticales y sin posibilidades de interacción continua" (Ojeda-Copa, 2017: s/p). ${ }^{7}$

En este trabajo proponemos una aproximación conceptual que entienda el movimiento social como una noción relacional, que comprenda la activación de las movilizaciones colectivas desde el lugar social que ocupan. En este sentido, el poder en movimiento es interpretable/explicable desde contextos materiales y simbólicos a escala regional, nacional y global. Sobre esta base se dispone de una serie de parámetros útiles tanto para identificar casos de estudio como para su correspondiente análisis. Estos criterios conceptuales centran el análisis en variables políticas de carácter simbólico, ligadas tanto a la opinión de agentes que tienen acceso a la propiedad y a la instrucción como a individuos que pertenecen a segmentos económicos subalternos de la población. Ambos tipos de sujetos participan de las crisis de legitimidad de manera particular, producto de las diferencias de escolaridad y de experiencia laboral. ${ }^{8}$ En este sentido, los estallidos sociales latinoamericanos se pueden leer como síntomas de la gestación de un "espacio tiempo transformativo" (Wallerstein, 1997), coyuntura que es interpretada por los sujetos de mayor instrucción como una oportunidad para activarse contra el statu quo.

Para evaluar esta propuesta analítica, consideraremos dos casos histórico-ilustrativos para realizar lo que Dieter Nohlen (2008) llama el proceso clásico de comparación. Si bien apuntamos más a considerar este planteamiento desde lo que se conoce como el multicaso (Gundermann, 2013), referimos a Nohlen debido al valor que presentan los análisis de trayectoria en la reflexión del valor heurístico de los conceptos de investigación. ${ }^{9}$ Para ello se

\footnotetext{
${ }^{7}$ En este sentido, Ojeda-Copa (2017) ha explicado que la participación dentro de la Web 1.0 correspondería a los modelos de participación vertical que se dan de arriba hacia abajo, donde solo un pequeño grupo puede incidir en la construcción del conocimiento y la información; dentro de la Web 2.0 y 3.0, este fenómeno se expresaría a través de la participación colectiva.

${ }^{8} \mathrm{Si}$ bien los saltos de la Web 1.0 a la 2.0 y a la 3.0 implicaron una transformación importante en el uso de internet como plataforma de los movimientos sociales, no podemos omitir el hecho de que en muchos países aún hay rezagos importantes de conectividad a internet y, en ese sentido, el analfabetismo tecnológico se extiende a grupos vulnerables, poblaciones sin conocimientos adquiridos, adultos mayores y las clases menos favorecidas que no tienen acceso a la red (Pérez-Zúñiga et al., 2015), además de otras problemáticas que representa el uso de internet, como las que tienen que ver con la libertad, la privacidad y la vigilancia (Flores-Márquez, 2017).

${ }^{9}$ Estimamos necesario enfatizar que el objetivo de este artículo es problematizar la noción de "movimiento social", con el fin de proponer una aproximación conceptual del objeto. Con base en este interés, se abordan los hechos ocurridos en México y en Chile como casos ilustrativos para ejemplificar el modelo propuesto.
} 


\section{Balajú}

contemplan los casos de México y Chile, considerando tanto su trayectoria como los hechos que en 2019 ocurrieron.

\section{México y Chile. Casos históricos ilustrativos}

Los movimientos sociales en México El caso de México se caracteriza por una diversidad de movimientos sociales cuyos antecedentes se observan en el siglo XIX, pero cuya presencia e intensidad se profundiza en la siguiente centuria. Los MS en México se intensificaron en la segunda mitad del siglo XX y, en su mayoría, fueron producto de la emergencia "obrero-campesina-popular", en cuya base organizativa se insertaron sectores fragmentados por la crisis económica que fincaron sus acciones en el combate a los grupos y cacicazgos regionales. Esto llevó a quienes han estudiado el tema a establecer una dicotomía entre movimiento social y movimiento político, donde los primeros constituían "movimientos de masas", "reivindicativos o sectoriales", en tanto que los segundos se ubicaban como grupos organizados "vinculados con la lucha explícita por el poder y, muy particularmente, con los partidos políticos y con los procesos electorales" (López, 1991: 23). Sin embargo, esta distinción complejizó el ejercicio analítico y empírico, por lo que la mayoría de los estudiosos de los MS en México dio lugar a una categorización más amplia, regularmente enmarcada en el proyecto de desarrollo económico que inició en el cardenismo y que se prolongó hasta principios de los ochenta, el cual adoptó un perfil "capitalista dependiente" y un "Estado centralista vertical", articulados en un sistema político que se legitimaba mediante el control de las demandas sociales y el bloqueo de las fuerzas independientes (Moreno, 2019: 37).

En las postrimerías de la Revolución, los MS emergieron como una manifestación de la sociedad civil para presionar a la sociedad política con demandas laborales que exigían la atención del Estado. Desde finales de los años cuarenta, repuntaron los movimientos obreros y de trabajadores, cuyas demandas se enfocaban a mejorar las condiciones laborales, el aumento salarial, impedir los despidos y el derecho a huelga. Para enfrentar esta efervescencia obrera, el alemanismo ${ }^{10}$ impuso dirigentes obreros y reprimió a los disidentes como método para impedir que las organizaciones laborales quedaran en libertad de actuar por cuenta propia. En la década de los cincuenta, la precariedad obrera aumentó y emergió una multitud de manifestaciones dirigidas a exigir mejores condiciones de vida. Destacan los movimientos

${ }^{10}$ Se refiere al sexenio presidencial de Miguel Alemán Valdés, de 1946 a 1952 [N. de la E.]. 


\section{Balajú}

cívicos que lograron la destitución de gobernadores; el surgimiento en Morelos del movimiento campesino armado denominado jaramillismo, encabezado por Rubén Jaramillo, el cual fue masacrado por el Estado; las huelgas de estudiantes del politécnico; las demandas y manifestaciones de los estudiantes normalistas; y el levantamiento del gremio ferrocarrilero que concluyó con una lucha fructífera por la independencia sindical, aunque también enfrentó la represión y la cárcel de sus dirigentes (Alonso, 2013: 87-88).

Sin embargo, el primer periodo de contestación y de impugnación política inicia con la emergencia del movimiento estudiantil de 1968 (de ahora en adelante ME68), el cual emergió como una expresión contra el autoritarismo y el deterioro social. La represión con saña que ejerció el Ejército sobre aquel lo convirtieron en el movimiento de mayor significado histórico hasta nuestros días, y, junto con el movimiento político-electoral de 1988, configuraron la ruta de transición política en México (Tamayo, 2019: 51). El ME68 representa una serie de signos que configuran un contexto político y sociocultural, bajo un régimen de partido de Estado, con una oposición clandestina, carente de canales de expresión, lo cual daba sustento a las demandas de libertad de expresión, liberación de presos políticos, de prensa y democratización de la educación (Olivier, Tamayo y Voegtli, 2013: 307).

La demanda estudiantil en México formó parte del oleaje de protestas y de transiciones estructurales que vivía buena parte de países en el mundo. En México, la culminación del "milagro mexicano", derivado de la industrialización por sustitución de importaciones, y la hegemonía empresarial nacionalista, bajo el esquema del Estado de bienestar, propició descontento por la emergente polarización social y el subempleo. Esto dio lugar a que el movimiento estudiantil se convirtiera en un canal expresivo de insatisfacción y de resistencia a esa realidad, el cual dio paso a un largo proceso de transición política y cultural en el país.

El ME68 enfrentó la raigambre autoritaria del Estado mexicano, que exhibió su intolerancia a la demanda y la disidencia estudiantil, generando espirales de violencia en contra de estudiantes de las dos principales instituciones educativas del país: la Universidad Nacional Autónoma de México y el Instituto Politécnico Nacional, así como de un amplio número de universidades de la capital y del resto del país. Desde su emergencia el 22 de julio, y durante los meses de agosto y de septiembre de 1968, el movimiento mostró capacidad organizativa a través del Consejo Nacional de Huelga $(\mathrm{CNH})$, y de movilización, hasta enfrentar la represión el 2 de octubre, en la Plaza de la Tres Culturas de Tlatelolco, diez días antes de la inauguración de los Juegos Olímpicos en México. Con un número incuantificable de muertos y más de dos 


\section{Balajú}

mil detenidos a manos del Ejército, prosiguió una etapa de violencia sistematizada de torturas y de secuestros contra los detenidos y sus familias, como medida represiva para desmovilizar y descabezar el movimiento.

El ME68 en México tiene un significado histórico importante en el proceso de transición, ya que exhibió los límites del sistema político mexicano, deslegitimó el régimen de partido de Estado y abrió canales de participación política a grupos que no encontraban condiciones para externar su oposición a la hegemonía vigente. Para muchos estudiosos del tema como Labastida y López (2008), el ME68, además de ser una experiencia pedagógica y aliento para nuevas formas de organización y de acción colectivas, que combaten por la democracia en México, representa un parteaguas en la transición política que vivió el país, porque expuso la estructura autoritaria del Estado y la necesidad de apertura de la participación en el sistema político.

Para el primer lustro de la década de los sesenta, se mantuvieron las movilizaciones que exigieron la liberación de los presos políticos, las que apoyaron a la Revolución cubana, la conformación del Movimiento de Liberación Nacional, la guerrilla rural, así como el movimiento magisterial y la emergencia de nuevo del movimiento médico, la mayoría de los cuales fueron reprimidos (Alonso, 2013: 87-88). La matanza de estudiantes a manos del Estado se replicó el 10 de junio de 1971, cuando un grupo de estudiantes que exigían libertad política y la democratización de la enseñanza fue reprimido por los Halcones, un grupo paramilitar del Estado, que asesinó a 120 estudiantes. La represión del Estado generó que un amplio sector de la sociedad considerara cerrada la vía de cambio institucional, por lo cual cientos de estudiantes universitarios dejaron las aulas y se integraron a organizaciones políticas clandestinas y a las guerrillas rural y urbana, que sumaban más de 30 agrupaciones y con presencia en 23 entidades del país. Frente a la expansión guerrillera en algunos estados, el Estado mexicano emprendió una estrategia de exterminio que ha sido denominada la "guerra sucia", la cual consistió en arrasar poblaciones, en detenciones masivas ilegales, en reclusión en cárceles clandestinas, persecución, tortura y desapariciones, acciones que excedieron cualquier límite de legalidad.

La imposición del modelo neoliberal en los albores de los años ochenta tuvo efectos económicos en amplios segmentos de la población, debido a que el aumento de la inflación deprimió los salarios. Esta contracción en la económica popular propició una serie de protestas en distintas direcciones, que coincidieron con el temblor de 1985, el cual destruyó una parte importante de la capital del país. La parálisis del gobierno frente al siniestro natural propició la 


\section{Balajú}

emergencia solidaria de la sociedad civil para ayudar a los damnificados y reconstruir el desastre. Otro elemento disruptivo que abonó a la transición política fueron las pugnas internas en el Partido Revolucionario Institucional (PRI), derivadas de la inconformidad de un sector influyente que exigía elecciones internas libres para nombrar candidato presidencial para las elecciones de 1988. La ruptura de este grupo con la dirigencia del partido dio paso a la conformación del Frente Democrático Nacional (FDN), el cual posibilitó la articulación de diferentes frentes de lucha en torno a Cuauhtémoc Cárdenas Solórzano, candidato de centro izquierda que enfrentó una elección fraudulenta y encabezó una álgida etapa en defensa del voto y de la democratización del país (Alonso, 2013: 88).

El FDN se convirtió en un espacio de articulación de diversos movimientos antineoliberales, integrados por sectores fragmentados por la crisis económica de 1982. Esta insurgencia "obrero-campesina-popular" fortaleció las bases de este amplio movimiento político, cuya finalidad fue la búsqueda del poder institucional, mediante la vía electoral. De acuerdo con López (1991: 23), estos movimientos se caracterizan por su participación en luchas explícitas por el poder, por su relación estrecha con los partidos políticos y dada su participación en las contiendas electorales, lo cual les da una fisonomía distinta a la de otros movimientos como los de masa o los reivindicativos y sectoriales. Al pasar del FDN, como un agrupamiento de coyuntura, a la conformación del Partido de la Revolución Democrática, este buscó asumir la doble fisonomía de "partido-movimiento", ya que, por un lado, buscaba mantener la competencia electoral y, por otro, mantenerse como un amplio movimiento que encabezara las demandas sociales derivadas de la imposición neoliberal, con lo cual se inició un larga etapa de confrontación con el gobierno salinista, que le costó al PRD cerca de 500 militantes asesinados. Un fenómeno similar se dio en 2011 con la conformación del Movimiento de Regeneración Nacional (Morena), encabezado por Andrés Manuel López Obrador, el cual articuló a un conjunto de organizaciones civiles, sociales y políticas para manifestarse contra el supuesto fraude en las elecciones presidenciales de 2006. El objetivo político electoral de este movimiento se cumplió al mantenerse movilizado contra el gobierno de Felipe Calderón, al que consideraron un presidente "espurio". Sin embargo, al convertirse en un partido político de centro izquierda y triunfar en las elecciones de 2018, ahora subyace como un partido sin capacidad crítica, sin agenda social y dependiente del liderazgo personalizado del presidente. 


\section{Balajú}

En suma, podemos considerar que tanto el movimiento estudiantil de 1968 como la conformación del FDN en 1988 representan un continuo de exigencias democráticas que se irían solidificando en los años subsiguientes, en medio de una álgida disputa entre el modelo neoliberal y el proyecto nacionalista revolucionario, representado por el gobierno lopezobradorista, en un contexto de demandas sociales crecientes y diversificadas (Tamayo, 2019: 59).

La imposición neoliberal desarticuló los basamentos del antiguo pacto social que mantenían el modelo estatista de modernización del país y que durante décadas contuvo las inconformidades y conflictos. Para la década de los noventa, la ruptura de esos basamentos generó una "pedacería social" (Zermeño, 1996: 25), que derivó en la emergencia y el desborde de diversos movimientos, los cuales empezaron a tener una incidencia importante en la sociedad. Las demandas contra la carestía, la inflación, a favor del trabajo y salarios dignos, dio protagonismo a movimientos de corte urbano-populares, así como a agrupaciones de deudores de la banca encabezados por El Barzón.

En ese contexto de crisis, desigualdad y desorden social (Zermeño, 1996: 23), emergió el Ejército Zapatista de Liberación Nacional (EZLN) en 1994 como un movimiento indígena autónomo y comunitario, cuya bandera inicial fue la lucha contra el exterminio de la cultura indígena. Anticapitalista y antineoliberal desde sus orígenes, cuestionó el olvido y el ultraje que el Estado y la clase en el poder ha instrumentado, y puso en marcha nuevas formas de vida alternativa al sistema capitalista. Este movimiento fue considerado un modelo de "guerrilla comunicacional", porque fue el primer movimiento de este tipo que utilizó las nuevas tecnologías de la comunicación y la información para establecer redes de apoyo a nivel internacional. Aunque inicialmente, en la Primera Declaratoria de la Selva Lacandona, sus demandas fueron la exigencia de trabajo, tierra, techo, salud, alimentación, educación, independencia, justicia, libertad, democracia y paz, estas fueron evolucionando hacia demandas políticas que exigían un gobierno de transición democrática, un nuevo constituyente y el respeto a los derechos y a la cultura indígena, hasta convertir la demanda de autonomía en su exigencia central y núcleo de su proyecto político, con el cual proponían erradicar la marginación, la discriminación y el machismo que afligían a las poblaciones indígenas del país.

No olvidemos, además, que a partir del surgimiento del Ejército Zapatista el uso de internet ha crecido a pasos agigantados en todo el mundo, principalmente en América Latina, donde la "penetración de la web alcanzaba en 2011 el 39\% de los latinoamericanos. En 2012 


\section{Balajú}

crece al 44.7 y para 2017, se espera supere el 63.4\%” (eMarketer 2013, en Pérez Zúñiga, Camacho Castillo y Arrollo Cervantes, 2015). En la actualidad, la gran mayoría de los países de América Latina tiene entre $60 \%$ y $85 \%$ de su población como usuarios de internet, lo que representa un incremento sorprendente y lo que explica, a su vez, el importante papel que las redes han tenido en los movimientos sociales a partir de la irrupción del EZLN en escena, cuyos alcances nacionales e internacionales fueron sorprendentes; más considerando que, en 1994, México contaba con una cobertura de penetración de la web donde solo 39 mil usuarios podían acceder a ella en todo el país, usuarios concentrados principalmente en los grandes centros urbanos (Schulz, 2014).

Las luchas y las demandas sobre las desigualdades sociales, a lo largo y ancho del continente, han sido visibilizadas, con mayor o menor fortuna, a través de la red y han mostrado el importante papel que las nuevas tecnologías de la información y de la comunicación pueden jugar en estos nuevos escenarios de protesta social, los cuales, además, devienen no solo en un espacio de activismo local, sino también de libre expresión, que abre la oportunidad de entrar en contacto y de "estar conectados con iniciativas similares en todo el mundo" (Flores Márquez, 2017: 124).

El movimiento zapatista fue el primero en enfrentar y en declararse en contra del neoliberalismo y de la globalización y en poner de nueva cuenta en la discusión nacional la condición marginal de los pueblos indígenas y el papel de estos como actores políticos. Hizo del proyecto de autonomía una alternativa de organización y de gobierno ante el neoliberalismo y la democracia representativa basado en el "mandar obedeciendo", a través del establecimiento de los "municipios autónomos", "Los Caracoles", mediante las "Juntas de Buen Gobierno" (Alonso, 2013: 87). Al sintetizar y nutrirse de las experiencias históricas de otros movimientos indígenas y no indígenas, a sus 27 años de existencia pública, y con múltiples ajustes en su organización interna, el EZLN ha sido pionero en "la construcción de poderes no estatales, dispersos y no centralizados": poderes comunales y espacios colectivos que tienen como objetivo generar una cultura política democrática basada en valores comunitarios, alejada de los vicios de la política oficial y proyectada más allá de los estrechos márgenes estatales (Ramírez, 2016b: 97).

Un vaso comunicante de estas experiencias autonómicas es la del municipio de Cherán, Michoacán, en la región conocida como Meseta Purépecha, desde 2011, cuando los comuneros purépechas se levantaron y se organizaron para defender sus bosques de talamontes 


\section{Balajú}

dependientes de Los Caballeros Templarios, un cártel del narcotráfico local. La construcción de esta autonomía vigente se dio a partir del desconocimiento de las autoridades constituidas y de los partidos políticos, así como el establecimiento de una nueva autoridad mediante asamblea general, compuesta por pobladores de la comunidad. El nuevo esquema organizativo comunal integra también un esquema de policía comunitaria, para frenar la explotación de sus bosques por parte de las autoridades y otro tipo de delitos infligidos por los cárteles del narcotráfico.

La embestida neoliberal, que privatizó la mayoría de las empresas estatales, dio paso a otros "movimientos de nueva generación" (León, 2015: 19) que emergieron de la sociedad civil, en el marco de distintas crisis nacionales como la ecológica, la económica, la educativa, la de seguridad y la de género. Esto propició una oleada de cuestionamientos al sistema económico y político, así como de movilizaciones, regularmente regionales, con diversas formas de manifestación que iban desde acciones pacíficas hasta radicales o violentas. Algunos de estos movimientos lucharon para impedir la privatización de la industria eléctrica y el petróleo en la primera década del siglo XXI; otros fueron movimientos campesinos, motivados por el autoritarismo del sistema político y por la defensa del territorio. Destaca entre ellos el movimiento formado por los ejidatarios de San Salvador Atenco, Estado de México, entre 2001 y 2002, al ser excluidos por las autoridades en la decisión de construir un aeropuerto en el valle de Texcoco. La defensa de las tierras en esta comunidad tuvo como respuesta la represión gubernamental, con lo cual se exhibió el poder del Estado neoliberal, expoliador de la tierra campesina y promotor de la acumulación de capital. Por su parte, la emergencia de la Asamblea Popular de los Pueblos de Oaxaca (APPO), en 2006, se constituyó en un pujante movimiento popular que, durante meses, enfrentó el autoritarismo local. En este caso, los gobiernos local y federal criminalizaron la protesta y violentaron las garantías individuales de los miembros y partidarios de la APPO, mediante detenciones ilegales, degradación en las detenciones y ejecuciones extrajudiciales (Alonso, 2013: 4; Tamayo, 2019: 64).

Otro flanco de descomposición social que ha propiciado la emergencia de nuevas manifestaciones colectivas ha sido la guerra contra el narcotráfico, cuyo resultado fue la atomización y expansión de los carteles de la droga. Con alrededor de 250 mil muertos, 61637 desaparecidos y un número no cuantificable de desplazados y "bajas por daños colaterales", tal como llamó el presidente Felipe Calderón a los muertos que nada tenían que ver con la guerra, el país se ha convertido en una "gran fosa clandestina" (Alberto Najar, 2019). Esta guerra 


\section{Balajú}

fallida contra el narcotráfico, emprendida por los gobiernos panistas y priistas (2006 a 2018), dio como resultado la conformación de una zona difusa, donde emergió una diversidad de colectivos que demandan seguridad al Estado. La "marcha blanca" contra la inseguridad en 2004, organizada por empresarios y con una amplia participación de clases medias acomodadas en la capital del país, había denunciado la falta de estrategias y de alternativas al problema por parte del gobierno federal. En 2011, emergió el Movimiento por la Paz con Justicia y Dignidad, encabezado por el poeta Javier Sicilia y compuesto por familiares de víctimas de la violencia -tanto asesinados como desparecidos- y organizaciones defensoras de derechos humanos, como respuesta a la violencia que se vive en el país por la estrategia de guerra contra el narcotráfico. Como parte de la sociedad civil organizada, este movimiento se convirtió en una de las voces más enérgicas, planteando la necesidad de cambiar la estrategia de combate al narcotráfico para frenar la violencia, así como de crear una Ley de Víctimas y Padrón de Desaparecidos para atender esos casos (Ramírez, 2016a: 31).

En esta expansión violenta del narcotráfico y en medio de la militarización del país, subyace la connivencia entre las autoridades del Estado y los grupos ilegales, sin que el Estado pierda su carácter represivo. Esto ha dado paso a una estela de violencia estatal: la desaparición de 43 estudiantes de la Escuela Normal Isidro Burgos, en Ayotzinapa, en Guerrero, en 2014; la ejecución extrajudicial, también en 2014, de 22 civiles por el Ejército en Tlatlaya, en el Estado de México; ejecuciones en 2015 de seis personas en Apatzingán y 22 en Tanhuato, en Michoacán, por la Policía Federal, entre otros muchos casos que son ejemplos visibles de crímenes contra la población civil donde el Estado tuvo una participación directa. Este ambiente de inseguridad generalizado ha propiciado la emergencia de distintos movimientos encaminados a exigir justicia al Estado. De octubre 2014 a la actualidad, los familiares de los 43 normalistas desparecidos de Ayotzinapa, tras considerar que "Fue el Estado" el autor responsable de la desaparición forzada, han intensificado las movilizaciones y mantenido presencia a nivel local, nacional e internacional, al mismo tiempo que se han articulado al movimiento zapatista o al magisterial para fortalecer sus demandas. En otro frente, han emergido colectivos regionales de "madres buscadoras", quienes se organizan para localizar los restos de sus hijos e hijas desparecidas, mediante la búsqueda de fosas clandestinas que, entre 2016 y 2019, ascendían a 3024 de acuerdo con datos vertidos por el gobierno federal (Aristegui Noticias, 2020). 


\section{Balajú}

En otro flanco generado por la guerra contra el narcotráfico, vemos el surgimiento de las denominadas policías comunitarias en estados como Guerrero, así como la aparición de las autodefensas en el estado de Michoacán que, desde 2013, y con base en la experiencia de Cherán, emergieron para combatir el crimen organizado, al margen o consentidas por el Estado. Estos grupos llegaron a establecerse en casi toda la geografía del estado; como respuesta, el gobierno federal procedió a institucionalizarlas y a convertirlas en guardias rurales. Actualmente, la acción del narcotráfico ha propiciado la reactivación de estos grupos, muchos de los cuales colaboran con los cárteles de la droga que se disputan los territorios en la entidad. ${ }^{11}$

Un nuevo movimiento estudiantil emergió en 1999, en la Universidad Nacional Autónoma de México (UNAM). Este movimiento "eminentemente cultural y simbólico" (Alonso, 2013: 90) fue considerado una manifestación de resistencia a las medidas del modelo neoliberal en materia educativa. Sus demandas se centraron en exigir la derogación del reglamento de pagos que planteaba un aumento en las cuotas universitarias, la apertura a un espacio de diálogo para la reforma integral de la universidad y el cese de la relación con el organismo de evaluación. Tras nueve meses de mantener la toma de las instalaciones centrales de la universidad, el movimiento fue desmantelado por el gobierno federal; quedó como demanda central la gratuidad de la educación en todos los niveles en el país y el cese a los intentos de privatización de esta (Alonso, 2013: 90). No obstante, también surgieron profundas dinámicas de exclusión entre los dos grupos que se disputaban el control del movimiento.

Con este antecedente de acción colectiva estudiantil, emergió en 2012 el movimiento \#Yosoy132 que, en la coyuntura de las elecciones de ese año, repudió al candidato del PRI, Enrique Peña Nieto, quien fue apoyado por Televisa, el monopolio televisivo con mayor cobertura nacional. Su aparición marcó el inicio en México del primer movimiento social de protesta a través de Facebook y Twitter (Pérez Zúñiga, Camacho Castillo y Arroyo Cervantes, 2015). Sus demandas se centraron en la democratización de los medios de comunicación y en la educación como vía de oportunidades para millones de mexicanos excluidos de ese derecho. Este movimiento, aunque se diluyó al concluir las elecciones, mostró nuevas estrategias ciudadanas para expresar desacuerdo con la política y con los actores políticos, que iban "desde

\footnotetext{
${ }^{11}$ Se aclara que esta colaboración ha surgido de manera velada, es decir, tras infiltración por elementos del crimen organizado y otros tipos de presión y negociación [N. de la E.].
} 


\section{Balajú}

la movilización social hasta la ironía y el sarcasmo en el campo político en general" (González Aguirre, 2013: 64, en Moreno, 2019, 44).

En 2020, como parte de las “emancipaciones sociales" (de Sousa, 2010) que sacudieron a América Latina en el marco de las protestas en Chile contra el neoliberalismo, se dio en México una multitudinaria protesta feminista en contra del sistema patriarcal que históricamente había marginado a la población femenina. Se articuló un discurso que cuestionaba la hegemonía machista y exigía la igualdad entre mujeres y hombres, junto con otras demandas en pro de la democratización de las relaciones sociales. Como en muchos países del continente americano y del mundo, en México hubo grandes manifestaciones de mujeres organizadas en torno a hashtags como \#UnDíaSinNosotras o \#UnDíaSinMujeres; cerca de 80 mil personas tomaron las calles de la Ciudad de México el 8 de marzo —Día Internacional de la Mujer - y se unieron al paro laboral convocado el día siguiente para crear consciencia en torno a los derechos de la mujer y en contra de la violencia de género.

Vistos en su conjunto, los movimientos sociales se han posicionado como la mayor oposición frente a la desigualdad generada por la hegemonía neoliberal, así como frente a los autoritarismos de los gobiernos de la alternancia, "las dictaduras personales y las unipersonales de los mercados financieros" (de Sousa, 2015: 23). Aunque los movimientos emergentes no han logrado articularse, lo cual explica por qué sus logros han sido parciales, con la expansión de la inseguridad, la desigualdad y la deslegitimación del Estado mexicano se mantiene latente la emergencia de nuevas expresiones colectivas organizadas frente a las distintas formas de dominación y de desigualdad que producen el sistema económico y político.

\section{Los movimientos sociales en Chile}

En Chile se presenta una serie de movimientos sociales cuya principal característica es su matriz cultural urbana. Teniendo antecedentes en el siglo XIX, con el movimiento mutualista, las mancomunales y, posteriormente, las "sociedades en resistencia", el fenómeno ganó en complejidad con el desarrollo del movimiento obrero durante la república parlamentaria entre los años 1891 y 1925 (Bauer, 1994; Salazar, 1989; Jocelyn-Holt, 1998).

El movimiento obrero generó brechas en el sistema de partidos de inicios del siglo XX, con la emergencia del Partido Comunista y, posteriormente, con la articulación del Partido Socialista (Faúndez, 1992). Junto a ello, con la crisis del modelo económico salitrero y el derrumbe del Estado oligárquico, se conformó en Chile un sistema político de nuevo cuño, 


\section{Balajú}

donde los partidos marxistas cumplirían un papel clave tanto en su fundación como en su trayectoria. Nacía así lo que Alfredo Rehren (2000) definió como la "democracia de partidos", un régimen político caracterizado por esquemas clientelares partido-cliente en los segmentos movilizados de la población. Así, los principales actores en los movimientos sociales del siglo XX estarían centrados en los partidos, cuyo objetivo final sería la competencia electoral para ganar cargos públicos. En este contexto político se desarrolló un nuevo proceso de modernización social, con base en un nuevo modelo económico fundado en la sustitución de importaciones y en la dirección económica del Estado (Faletto, Ruiz y Zemelman, 1972; Faúndez, 1992).

De esta manera, los movimientos sociales en el siglo XX estarían bajo la sombra de los partidos. El clientelismo político dominante en Chile permitió convertir a estas organizaciones en la columna vertebral del sistema político chileno (Garretón, 1983; Moulian, 1993; Scully, 1992), de tal modo que detrás de todo poder en movimiento se encontraría la acción de un partido político. Este hecho tuvo consecuencias en la estructura de poder en el país: los cargos públicos -tanto en el poder ejecutivo como en el legislativo- eran de elección popular. A medida que se fue extendiendo la ciudadanía en el siglo XX, los cargos fueron más competidos políticamente, lo que provocó numerosos conflictos sociales (Faúndez, 1992; Scully, 1992; Moulian, 1993). La misma variable jugó un papel clave en el armazón de los partidos mismos. Las élites de partido controlaban las plazas electorales en los distintos distritos y circunscripciones del país (Moulian, 1993; Scully, 1992). Este hecho generó la emergencia tanto de caudillismos electorales como de distintos niveles de intermediación política local/supralocal, de tal manera que se produjo una articulación entre los agentes parroquiales y la acción a escala nacional de los partidos políticos (Valenzuela, 1977).

Al finalizar la década de los cincuenta comenzó un nuevo ciclo de movimientos sociales en el país. El fenómeno estuvo vinculado a la emergencia del Partido Demócrata Cristiano (PDC o DC), organización que, producto de su estructura orgánica - un partido de máquina-, generó una competencia centrífuga en las elecciones de los años sesenta y setenta (Sartori, 1990; Scully, 1992; Moulián, 1993). La centrifugación de la competencia política movilizó tanto a los tradicionales grupos urbanos organizados, como a nuevos actores. Entre las nuevas colectividades movilizadas por el PDC destacaban el campesinado -históricamente excluido de los derechos laborales urbanos y vinculados clientelarmente a los partidos de derecha- y los pobres de las ciudades (Faúndez, 1992). Los primeros vivieron la sindicalización rural dirigida 


\section{Balajú}

por los democratacristianos, organizando a su vez a estos grupos en cooperativas para la producción agrícola. Los pobres urbanos, en cambio, se integraron al mercado electoral controlado por la DC y, junto al campesinado, generaron una nueva plaza fuerte electoral, fenómeno que amenazó las plazas fuertes electorales de los partidos marxistas (Scully, 1992). Esta competencia se radicalizó durante el gobierno de Salvador Allende (1970-1973), hecho que condujo al quiebre institucional de 1973 y a la instalación de un régimen político autoritario (Valenzuela, 1989; O’Donnell, 1972; Varas, 1987; Huneeus, 2001).

Bajo el régimen autoritario, se castigó el movimiento social mediante medidas represivas de persecución, exilio y exterminio de sus actores (Varas, 1987). Aunado a ello se implementó un modelo económico de corte neoliberal, que prometía a la ciudadanía alcanzar el desarrollo del país en una serie de etapas. No obstante, a pesar del esfuerzo de la dictadura cívico-militar por destruir los partidos políticos, estos no desaparecieron de la escena nacional: la prolongada historia de estos en la arena política del país terminó pesando más que la acción del autoritarismo (Huneeus, 2001). De esta manera, se generó una nueva coyuntura política para su reemergencia con la crisis económica de los años ochenta. Con el desplome económico nacional — producto de la quiebra de la reducida industria que aún operaba en el país, junto al ciclo de crisis económicas globales - surgió una nueva movilización fundada inicialmente en la improvisada protesta social urbana que puso en jaque al régimen autoritario. Fue esta movilización la que permitió el retorno de los partidos a la escena, desde su presencia política en las calles -incluyendo, en algunos casos, la formación de una guerrilla urbana contra el régimen- hasta la articulación de un movimiento de oposición electoral, hecho que cristalizó en 1988 con el plebiscito y en 1989 con la elección presidencial y parlamentaria.

Con el proceso de redemocratización (1988-1990), los partidos volvieron a la escena política en calidad de actores dominantes. A la par de esto, el país se desmovilizó tras la retirada del régimen autoritario. Sin embargo, se generó tempranamente una situación de "malestar social" en la población (Moulian, 1997), producto del incumplimiento de las metas trazadas por la oposición política a la dictadura. En este terreno, tanto la filiación de clases como el vínculo con una condición material y simbólica a nivel local/regional motivaron la movilización de una serie de colectividades en los primeros años de la década de los noventa, evidenciando las fracturas sociales del país, con sus correspondientes consecuencias políticas (Moulian, 1997; Barozet, Espinoza, Holz y Sepúlveda, 2009; Mac-Clure, Barozet y Maturana, 2014). Uno de los primeros hitos de este malestar se observa en la emergencia de los 


\section{Balajú}

movimientos indígenas a partir de 1992. Esta "emergencia indígena", como lo definió José Bengoa (2007), condujo primero al cuestionamiento del quinto centenario del hito de $1492 \mathrm{y}$, posteriormente, al movimiento autonomista en la región de Araucanía (Tricot, 2009; Pairicán, 2014), junto a otras movilizaciones por reconocimiento indígena en el resto del territorio nacional (Vergara y Gundermann, 2012; Gundermann, González y Durston, 2018).

Junto a ello, este movimiento también informó de la complejidad que implica la distinción entre agentes subalternos y sujetos de élite en la movilización, tal como se observa en el abordaje de la intelectualidad indígena por parte de Claudia Zapata (2005, 2007, 2008), o lo que Jaime González (2018) llama “intelectualidad étnica”. Para ambos autores, los agentes intelectuales cumplen un papel relevante en la construcción de discursos étnicos, productos ideológicos fundamentales para un proceso de movilización social.

A este fenómeno, se sumaron otros movimientos sociales que, a juicio de Gabriel Salazar (2020), se caracterizaron por su sello "ciudadanista". Este nuevo poder en movimiento se distinguiría de sus homólogos del pasado por estar desvinculados parcial o totalmente de los partidos, mostrando frente a estos una verdadera rebeldía de la ciudadanía. De esta manera surgirían movilizaciones sociales de alta complejidad, producto de la combinación de grupos diferentes en la misma escena territorial, tal como ocurrió en el movimiento ciudadano en la localidad de Calama, región de Antofagasta (Penaglia y Valenzuela, 2014). Fue así como se desarrolló lo que Esteban Valenzuela (2015) definió como "territorios rebeldes" en Chile, fracturas motivadas por lo que él conceptuó como "clivaje regionalista", dando cuenta de la territorialización y regionalización de la base de numerosos conflictos y movimientos sociales de nuevo cuño en el país. Este hecho se evidenció tanto en los distintos discursos indígenas por demandas etnoterritoriales (González, 2017; González y Valenzuela, 2017) como en movimientos sociales con sello universitario, como el movimiento estudiantil de 2011 o el movimiento feminista de 2018. En estos movimientos de corte urbano, destaca la filiación ideológica de izquierda y la participación en clubes deportivos con una mayor tendencia a participar en la protesta juvenil (Rozas y Somma, 2020), así como el nexo entre identidades, emociones y participación social en estudiantes universitarios (Villagrán, Reyes y Wlodarczyk, 2019), que tuvieron como soporte de acción y movilización las redes sociales.

Desde 1990 en adelante, se desarrolla lo que Jaime Lindh, Jorge Fábrega y Jorge González (2019) llaman un proceso de "polarización ideológica" a nivel político, socioeconómico y generacional, dando cuenta del hiato generado en la población entre 1990 y 


\section{Balajú}

2017. Un último hito relevante fue el mayo feminista de 2018, movimiento social que, a juicio de Catherine Reyes-Housholder y Beatriz Roque (2019), constituye un "movimiento emergente" que cuestionó el modo en que ha sido distribuido el poder entre hombres y mujeres y desafió el poder político y social al criticar las brechas de género persistentes en la sociedad chilena.

El gran elemento en común de todos los movimientos emergentes en los últimos treinta años es lo que Gabriel Salazar (2020) llama la condición “ciudadana” de estos: es decir, un poder en movimiento desvinculado parcial o totalmente de los partidos políticos. Desde esta perspectiva, Salazar define el estallido social del 18 de octubre de 2019 como "reventón social", en que confluyeron los distintos movimientos sociales generados en las últimas décadas, pero que representan las aspiraciones de una colectividad de origen colonial que el autor llama "bajo pueblo" chileno. Así, el movimiento social generado en días recientes es resultado de la convergencia - desde la larga duración- de una serie de movimientos de origen popular que cristalizaron en el reventón social de octubre y que han puesto al país en un contexto de revolución social y política. Desde esta óptica, se puede decir que el caso chileno da cuenta de un proceso social complejo, debido tanto a la prolongada trayectoria de los movimientos sociales en Chile como a la coyuntura crítica que implica la crisis de legitimidad que se ha generado en la totalidad de las instituciones. Junto a ello, Chile también nos muestra la complejidad que implica la distinción entre agentes subalternos y actores de élite en los movimientos, tal como se apreció en el caso de México.

Podemos afirmar que, en Chile, así como en México (y en el mundo), la aparición del activismo en redes sociales ha representado un importante avance en los procesos de organización, movilización y participación de los MS. Algunas de las trasformaciones más importantes se pueden señalar en los siguientes puntos expresados por Pérez-Zúñiga, Camacho Castillo y Arroyo Cervantes (2015, s/p):

1. Proliferación y ramificación de los colectivos sociales; 2. Horizontalidad en las redes; 3. Propensión a formar coaliciones [en torno a proclamas comunes tanto a nivel nacional como a nivel mundial]; 4. Subsistencia dependiendo de los hechos [protestas con gran dinamismo que desaparecen con cierta rapidez, pero dan origen al surgimiento de nuevos movimientos sociales]; 5. Universalismo y especialización de las causas; 6. Poder de organización [organización horizontal que además puede manifestarse en diferentes ciudades y diferentes países de manera simultánea, así como la organización de pequeños grupos o colectivos locales 


\section{Balajú}

dispersos]; 7. Estrategias no localizadas de ideologías compartidas [que buscan coincidencias y perspectivas análogas, pero no necesariamente idénticas], y 8. Multiplicidad de identidades [la posibilidad de participar en distintos movimientos sociales e interactuar con individuos de distintas ideologías evitando conflictos internos].

A esto se puede agregar: desconfianza hacia los medios de comunicación convencionales, repudio a los partidos políticos -sin importar ideologías-y reticencia ante los líderes morales. ${ }^{12}$

\section{Reflexiones finales}

Este ensayo centró su reflexión en el concepto de movimiento social con el fin de analizar las semejanzas entre las recientes movilizaciones sociales en México y en Chile. En función de esta problemática, sugerimos la existencia de similitudes observables en dos niveles de análisis: 1) el contexto de crisis de legitimidad del orden establecido, y 2) el manejo medial a través de redes digitales por parte de los movimientos. En este sentido, legitimidad/ilegitimidad y opinión medial constituyen las claves explicativas de la activación de los movimientos.

El análisis se valió de los aportes realizados tanto por la antropología cultural como por la teoría del sistema mundial. Desde esta perspectiva, se estableció una distinción conceptual entre cultura política e identidad política para comprender las situaciones de crisis de legitimidad y, sobre esta base, explicar la emergencia de este poder en movimiento. Se complementó esta reflexión considerando variables sistémicas globales desde el concepto de "geocultura" formulado por Wallerstein (2006). Desde esta aproximación se definió el concepto de movimiento social como un conjunto de prácticas cosmopolitas, comportamientos que bajo ciertas condiciones - crisis de legitimidad de la cultura política vigente- pueden reorientar la cultura cívica en una sociedad. Estas acciones estarían vinculadas a sujetos urbanos, cosmopolitas y con altos grados de instrucción. ${ }^{13}$ Estos agentes, junto a individuos

\footnotetext{
${ }^{12}$ Ojeda-Copa (2017: 20), siguiendo a Castells, define otras características de los movimientos sociales actuales de la siguiente manera: "Si bien nacen en las redes, se convierten en movimientos en la ocupación del espacio urbano; son locales y globales a la vez; viven en un tiempo 'atemporal', entre el ahora y el proyecto futuro; nacen de forma espontánea, en general con una chispa de indignación; son virales, siguiendo la lógica de las redes mismas; pasan de la indignación a la esperanza a través de la deliberación; no tienen líderes, pero aun así existe una unidad, aunque la comunidad es todavía un objetivo en construcción; son altamente autorreflexivos; raramente son programáticos y apuntan más bien a cambiar los valores de la sociedad".

${ }^{13}$ En torno a las prácticas cosmopolitas de los agentes clave en los movimientos sociales en América Latina, se ha escrito mucho desde la investigación de los movimientos indígenas. En este terreno, Luis Vázquez León (1992), María Eugenia Vargas (1994) y Natividad Gutiérrez (2001) destacaron el papel de la intelectualidad étnica en este accionar, sujetos caracterizados por una diversidad de grados de instrucción tributarios de la academia occidental
} 


\section{Balajú}

subalternos, conformarían los movimientos sociales de nuevo cuño presentes en los últimos dos años, de tal manera que la emergencia "desde abajo" de los contrapuntos al orden establecido estaría orientado por la opinión -desde soportes tecnológicos digitales- de estudiantes y profesionales universitarios.

Desde esta perspectiva se analizó la significación/resignificación de la legitimidad de las instituciones y de los estilos de hacer política gubernamental. Se propuso un concepto relacional de movimiento social que permitiera comprender estos fenómenos desde el lugar social que ocupan. Así, podemos entender el objeto desde variables de poder simbólico vinculadas a la opinión de agentes con ciertos grados de instrucción, que interactúan con individuos subalternos. Ambos tipos de sujetos participan de las crisis de legitimidad de manera particular, producto de las diferencias experienciales en el terreno de la escolaridad y de la vida laboral. En este sentido, los estallidos sociales en México y en Chile se pueden leer como síntomas de la gestación de un "espacio tiempo transformativo" (Wallerstein, 1997), coyuntura que es interpretada por los sujetos de mayor instrucción como una oportunidad para activarse contra el statu quo.

Así, el poder en movimiento es interpretable y explicable desde contextos materiales y simbólicos a escala regional, nacional y global, tal como se observó en los casos históricos ilustrativos contemplados aquí. En México se aprecia la complejidad de los movimientos debido a la matriz histórica y cultural del país. Los distintos grupos que han participado en movilizaciones de contrapunto al orden establecido presentan orígenes prehispánicos y coloniales, como ha sido evidente en los movimientos rurales o campesinos en la revolución de 1910 y, después de ella, la emergencia indígena en los últimos treinta años, la cual se convirtió en el principal motor de oposición a los gobiernos neoliberales; así como las múltiples expresiones de grupos movilizados para buscar a sus familiares desaparecidos en la guerra contra el narcotráfico. Una mención semejante se puede hacer para el caso de Chile. A pesar de las grandes diferencias entre los dos países, resulta evidente que la condición subalterna de estos movimientos sociales presenta matices similares a la hora de establecer una distinción entre los agentes que participan de la movilización. En este terreno, estudiantes y profesionistas universitarios portan una cultura académica y cosmopolita que les ha permitido orientar los movimientos desde el terreno de la opinión en y a través de los medios digitales. Frente a la

y cosmopolita. Comentarios semejantes enuncian Henri Favre (1996), Willem Assies (1999) y José Bengoa (2007) en torno a estos agentes. 


\section{Balajú}

evidente crisis de legitimidad de las instituciones sociales y las formas de hacer política formal, las redes sociales digitales se convierten en el soporte tecnológico por el cual se emiten opiniones estudiantiles y profesionales.

La particularidad del caso chileno se encuentra en el papel que cumplieron los estudiantes de secundaria en el inicio del estallido social de octubre de 2019. En este sentido, pareciera ser que la cultura cosmopolita que opera en los agentes de alta instrucción se encuentra presente tanto dentro del sistema educacional más amplio como en las redes sociales digitales que permiten la comunicación entre individuos. Una politología de la legitimidad de las instituciones sociales debe hacerse cargo de la investigación de esta problemática. Tal como sostendría Dieter Nohlen (1991, 2013), la política constituye ante todo un fenómeno humano, lo que lleva a que sus instituciones se funden en las creencias y valoraciones de los pueblos. De esta manera, la vigencia de un estilo de hacer política dependerá de la interpretación que realicen las colectividades humanas en un contexto espacial y temporal.

Finalmente, la red ha terminado por convertirse en un gran surtidor de agendas mundiales alternativas, de características análogas y (en ocasiones) comunes, que han saltado "la barrera del territorio, redimensionando la relación tiempo-espacio (fronteras) y dando carta de naturaleza a un nuevo modelo comunicativo basado en: 1) la gestión de flujos de información, 2) la organización horizontal, 3) bidireccionalidad de la información que circula por el conjunto de redes técnicas y sociales, 4) la inmediatez, y 5) el trabajo e inteligencia colectivos" (Sádaba y Roig; 2007: 119). Estos están trascendiendo los modelos organizativos clásicos que se caracterizaron por la verticalidad de su organización y participación, que fluían desde la decisión de los líderes hacia la obediencia de los afiliados y, por lo mismo, eran representativos y no colectivos. Este cambio de dimensión abre una nueva perspectiva a los movimientos sociales en lo que resta del siglo veintiuno.

\section{Referencias}

ALMOND, G. y VERBA, S. (1963). The Civic Culture. Political Attitudes and Democracy in Five Nations. Princeton: Princeton University Press.

ALONSO, J. (2013). Repensar los movimientos sociales. México: CIESAS.

ARISTEGUI NOTICIAS (Redacción) (2020, 13 de junio). "Datos de horror: hay 3024 fosas clandestinas en México". 


\section{Balajú}

ASSIES, W. (1999). "Pueblos indígenas y reforma del Estado en América Latina". En W. Assies, G. Van der Haar y A. Hoekema (eds.), El reto de la diversidad. Zamora: El Colegio de Michoacán, 1-16.

BAROZET, E., V. ESPINOZA, R. HOLZ y D. SEPÚLVEDA (2009). Estratificación social en regiones: ¿qué oportunidades ofrecen las regiones en Chile? Santiago: Subsecretaría de Desarrollo Regional/Universidad de Chile, Proyecto Desigualdades. http://www.subdere.gov.cl/sites/default/files/documentos/articles-82941_recurso_4_0.pdf.

BAUER, A. (1994). La sociedad rural chilena. Desde la conquista española a nuestros días. Santiago: Andrés Bello.

BENGOA, J. (2007). La emergencia indígena en América Latina. Santiago: Fondo de Cultura Económica.

CANDÍA, G. (2014). "Las redes sociales y su influencia en los movimientos sociales”. En M. Ramos, A. Alvarado, W. López, M. Solís y C. López (eds.), Estudios organizacionales y desarrollo regional. Tópicos selectos de recursos. Sucre: CECOFRAN-Bolivia.

CASTELLS, M. (1999). La era de la información. Economía, sociedad y cultura. El poder de la identidad, Vol. II. México: Siglo XXI.

CASTELLS, M. (2009). Comunicación y poder. Madrid: Alianza Editorial.

DE SOUSA, B. (2010). Para descolonizar Occidente. Buenos Aires: CLACSO.

DE SOUSA, B. (2015). Revueltas de indignación y otras conversas. La Paz: Proyecto ALICE, Consejo Europeo de Investigación.

FALETTO, E., E. RUIZ y H. ZEMELMAN (1972). Génesis histórica del proceso político chileno. Santiago: Quimantu.

FAÚNDEZ, J. (1992). Izquierdas y democracia en Chile, 1932-1973. Santiago: Bat.

FAVRE, H. (1996). El indigenismo. México: Fondo de Cultura Económica.

FLORES-MÁRQUEZ, D. (2017). “Movimientos sociales e internet en México”. En G. Pleyers y M. Garza-Zepeda (coords.), México en movimientos. Resistencias y alternativas. México: Miguel Ángel Porrúa/Universidad Autónoma Benito Juárez de Oaxaca/Universidad Autónoma de Ciudad Juárez.

GARRETÓN M., M. A. (1983). El proceso político chileno. Santiago:Flacso.

GIDDENS, A. (2000). Sociología. Madrid: Alianza.

GONZÁLEZ, J. (2018). "Intelectualidad étnica. Propuesta teórico-metodológica de un objeto de indagación”. Temas Sociológicos 23, 273-305. 


\section{Balajú}

GONZÁLEZ, J. (2017). “Aymaras ante el clivaje regionalista en Chile: etnicidad, recursos y autonomía polisémica". Revista Encrucijada Americana 9(1), 55-68.

GONZÁLEZ, J. y E. VALENZUELA (2017). “Mapa de demandas etnoterritoriales indígenas en Chile: mapuches-rapa nuis-diaguitas rebeldes, aymaras-atacameños consociativos". Revista Iberoamericana de Estudios Municipales 8(16), 79-107.

GONZÁLEZ, J. (2013). “Jóvenes, social media y movilización social. El \#yosoy132 y la deconstrucción del espacio público en México". En M. Nájera (coord.), Movimientos Sociales, autonomías y resistencia. México: Universidad de Guadalajara. CaliforniaMexico Studies Center, California State University, 63-82.

GUNDERMANN, H., H. GONZÁLEZ y J. DURSTON (2018). "Interetnicidad y relaciones sociales en el espacio atacameño". Estudios Atacameños (57), 161-179.

GUNDERMANN, H. (2013). "El método de los estudios de caso”. En M. L. Tarrés (coord.), Observar, escuchar y comprender. Sobre la tradición cualitativa en la investigación social. México: El Colegio de México y Flacso, 231-264.

GUTIÉRREZ, N. (2001). Mitos nacionalistas e identidades étnicas: los intelectuales indígenas y el Estado mexicano. México: Conaculta.

HARRIS, M. (2003). Antropología cultural. Madrid: Alianza.

HABERMAS, J. (2009). Historia y crítica de la opinión pública. Barcelona: Gustavo Gili.

HUNEEUS, C. (2001). El régimen de Pinochet. Santiago: Sudamericana.

JOCELYN-HOLT, A. (1998). El Chile perplejo. Del avanzar sin tranzar al tranzar sin parar. Santiago: Ariel.

LABASTIDA, J. y LÓPEZ, M. (2008). “México: una transición prolongada (1988-1996/97)”. En Cordera R. (coord.), El papel de las ideas y las políticas en el cambio estructural en México. México: Fondo de Cultura Económica, 121-187.

LEÓN, A. (enero-junio 2015). "Los nuevos movimientos sociales en México en el siglo XXI. Estudio exploratorio”. Revista Espacios Transnacionales (4), 14-25.

LINDH, J., J. FÁBREGA y J. GONZÁLEZ (2019). "La fragilidad de los consensos. Polarización ideológica en el Chile post Pinochet”. Revista de Ciencia Política 39(1), 99-127. LÓPEZ, A. (1991). “Movimientos políticos, movimientos sociales”. En V. Gabriel y M. Canto (coords), El estudio de los movimientos sociales: teoría y método. México: El Colegio de Michoacán/Universidad Autónoma Metropolitana, 21-36. 


\section{Balajú}

MAC-CLURE, O., E. BAROZET y V. MATURANA (2014). "Desigualdad, clase media y territorio en Chile: ¿clase media global o múltiples mesocracias según territorios?”, Eure 40(121), 163-183.

MARTÍNEZ, J. (2015). “El relator de la UNU concluye que la tortura es 'generalizada' en México”. El País. http://internacional.elpais.com/internacional/2015/02/26/actualidad/1424971709_730815.h $\underline{\mathrm{tml}}$.

MELUCCI, A. (1999). Acción colectiva, vida cotidiana y democracia. México: El Colegio de México.

MEYER, L. (2012). Los grupos de presión extranjeros en el México revolucionario, 19101940. México: El Colegio de México.

MORENO, M. (2019). “El Estado y los movimientos sociales en el México contemporáneo: continuidad o replanteamiento". En Aguilar, F. (coord.), Los movimientos sociales en la vida política mexicana. México: IIS-UNAM, 8-29.

MOULIAN, T. (1997). Chile actual. Anatomía de un mito. Santiago: LOM-Universidad ARCIS.

MOULIAN, T. (1993). La forja de ilusiones: el sistema de partidos, 1932-1973. Santiago: Universidad ARCIS-Flacso.

NAJAR, A. (2019, 6 de febrero). "'México es una enorme fosa clandestina': por qué la desaparición de personas se convirtió en una grave crisis humanitaria”. $B B C$.

NOHLEN, D. (2013). "Presidencialismo versus parlamentarismo", Revista Latinoamericana de Política Comparada 7, 61-76.

NOHLEN, D. (2008). Conceptos y contexto. En torno al desarrollo de la comparación en ciencia política. Working Paper 265, 1-40.

NOHLEN, D. (1991). "Presidencialismo versus parlamentarismo en América Latina", Revista de Estudios Políticos (74), 43-54.

O’DONNELL, G. A. (1972). Modernización y autoritarismo. Buenos Aires: Paidós.

OLIVIER, G., TAMAYO, S. y VOEGTLI, M. (2013). "La démobilisation étudiante au Mexique: le double visage de la répression (juillet-décembre 1968)". European Journal of Turkish Studies (17). https://doi.org/10.4000/ejts.4819.

OJEDA-COPA, A. (diciembre 2017). "Movimientos sociales e internet: de la política centralizada a la política distributiva", Punto Cero 22(35), 9-23. 


\section{Balajú}

PAIRICÁN, F. (2014). Malón. La rebelión del movimiento mapuche, 1990-2013. Santiago: Pehuén.

PENAGLIA, F. y E. VALENZUELA (2014). "Rebeldía en Calama: desafío al orden centralista chileno en un contexto de boom minero", Revista Mexicana de Ciencias Políticas y Sociales 59(222), 161-185.

PÉREZ-ZÚÑIGA, R., O. CAMACHO CASTILLO y G. ARROYO CERVANTES (septiembre 2014-febrero 2015). "Las redes sociales y el activismo". Paakat: Revista de Tecnología y Sociedad 4(7).

RAMÍREZ, A. (2016a). “A manera de introducción. Los movimientos sociales en los albores del siglo XXI”. En Ramírez, A. (coord.), Movimientos sociales en México. Apuntes teóricos y estudios de caso. México: UAM/CONACYT/ Colofón/RED, 16-55.

RAMÍREZ, A. (2016b). "Pensar los movimientos sociales en el siglo XXI. Una reflexión desde el neozapatismo". En Ramírez, A. (coord.), Movimientos sociales en México. Apuntes teóricos y estudios de caso. México: UAM/CONACYT/ Colofón/RED, 61-107.

RAMÍREZ, R. y J. GONZÁLEZ (2018). "Ruta crítica para el estudio de las culturas políticas en América Latina" Revista Encrucijada Americana 10(2), 25-46.

REHREN, A. (2000). Clientelismo político, corrupción y reforma del Estado en Chile. Documento de Trabajo 305. Santiago: CEP, 131-164.

REYES-HOUSHOLDER, C. y B. ROQUE (2019). “Chile 2018: desafíos al poder de género desde la calle hasta La Moneda”. Revista de Ciencia Política 39(2), 191-215.

RIECHMAN, J. y FERNÁNDEZ, F. (1994). Redes que dan libertad. Introducción a los nuevos movimientos sociales. Barcelona: Paidós.

ROZAS, J. y N. SOMMA (2020). "Determinantes de la protesta juvenil en Chile", Revista Mexicana de Sociología 82(3), 673-703.

SÁDABA-RODRÍGUEZ, J. y G. ROIG-DOMÍNGUEZ (2005). "Las otras voces de la red. Comunicación política y contrainformación global”. En P. López-López y J. GimenoPerelló, Información, conocimiento y bibliotecas en el marco de la globalización neoliberal. Biblioteconomía y Administración Cultural 119. Gijón: Trea.

SALAZAR, G. (2020). "El reventón social en Chile. Una mirada histórica”. Nueva Sociedad (288). https://nuso.org/articulo/protestas-Chile-estudiantes-neoliberalismo/.

SALAZAR, G. (1989). Labradores, peones y proletarios (siglo XIX). Santiago: Sur. 


\section{Balajú}

SARTORI, G. y L. MORLINO (1999). La comparación en las ciencias sociales. Madrid: Alianza.

SARTORI, G. (1990). Partidos y sistemas de partidos. Buenos Aires: Paidós.

SCHULZ, M. (2014). "Nuevos medios de comunicación y movilización transnacional: el caso del Movimiento Zapatista", Perfiles Latinoamericanos 44.

SCULLY, T. (1992). Los partidos de centro y la evolución política chilena, Santiago: CieplanNotre Dame.

SEN, A. (2008). Identidad y violencia. La ilusión del destino. Buenos Aires: Katz Editores.

TAMAYO, S. (2019). “Ciclos de protesta en México, siglo XXI. La fragmentación de la política”. En F. Aguilar (coord.). Los movimientos sociales en la vida política mexicana. México: UNAM, 51-92.

TEJERA GAONA, H. (1996). "Cultura política: democracia y autoritarismo en México". Nueva Antropología 15(50), 11-21.

TARROW, S. (1997). El poder en movimiento, Madrid: Alianza.

TOURAINE, A. (1997). ¿Podremos vivir juntos? México: Fondo de Cultura Económica.

TOURAINE, A. (2006). “Los movimientos sociales”. Revista Colombiana de Sociología (27), 255-278.

TRICOT, T. (2009). "Lumako: punto de inflexión en el desarrollo del nuevo movimiento". Historia Actual Online (19), 77-96.

VALENZUELA, E. (2015). Territorios rebeldes. Autonomías versus presicracia centralista. Santiago: Universidad Alberto Hurtado.

VALENZUELA, A. (1989). El quiebre de la democracia en Chile. Santiago: Flacso.

VALENZUELA, A. (1977). Political brokers in Chile: local government in a centralized policy. Durham: Duke University Press.

VARAS, A. (1987). Los militares en el poder. Régimen y gobierno militar en Chile. 19731986. Santiago: Flacso-Pehuén.

VARGAS, M. E. (1994). Educación e ideología. Constitución de una categoría de intermediarios en la comunicación interétnica. El caso de los maestros bilingües tarascos (1964-1982). México: CIESAS, Colección Miguel Otón de Mendizábal.

VÁZQUEZ, L. (1992). Ser indio otra vez. La purepechización de los tarascos serranos. México: Conaculta. 


\section{Balajú}

VERGARA J. I. y H. GUNDERMANN (2012). “Conformación y dinámica interna del campo identitario regional en Tarapacá y Los Lagos”. Chungara 1 (44), 115-134 [versión electrónica].

VILLAGRÁN, L., C. REYES y A. WLODARCZYK (2019). “Acciones de participación social, identidad y emociones de estudiantes chilenos de una universidad privada". Polis (53), 78-93.

WEBER, M. (2002). Economía y sociedad. México: Fondo de Cultura Económica.

WALLERSTEIN, I. (2006). Análisis de sistemas-mundo. Una introducción. México: Siglo XXI.

WALLERSTEIN, I. (1997). "El espacio tiempo como base del conocimiento". Análisis Político (32), 3-15.

WALLERSTEIN, I. (1979). El moderno sistema mundial. La agricultura capitalista y los orígenes de la economía-mundo europea en el siglo XVI. Madrid: Siglo XXI.

ZAPATA, C. (2008). "Los intelectuales indígenas y el pensamiento anticolonialista", Discursos/prácticas 2, 113-140.

https://www.discursospracticas.ucv.cl/pdf/numerodos/claudia_zapata_silva.pdf.

ZAPATA, C. (2007). "Memoria e historia: el proyecto de una identidad colectiva entre los aymaras de Chile". Chungara 2 (39), 171-183 [versión electrónica].

ZAPATA, C. (2005). "Origen y función de los intelectuales indígenas". Cuadernos Interculturales 4 (3), 65-87 [versión electrónica].

ZERMEÑO, S. (1996). La sociedad derrotada. El desorden mexicano de fin de siglo. México: UNAM y Siglo XXI. 